\title{
Thermal analysis of a winding turn-to-turn fault in PM synchronous machine
}

\section{Citation for published version (APA):}

Smeets, J. P. C., Soulard, J., \& Lomonova, E. (2010). Thermal analysis of a winding turn-to-turn fault in PM synchronous machine. In Proceedings of the 2010 19th International Conference on Electrical Machines (ICEM), September 6-8, 2010, Rome, Italy (pp. 1-6). Institute of Electrical and Electronics Engineers. https://doi.org/10.1109//CELMACH.2010.5608010

DOI:

10.1109/ICELMACH.2010.5608010

Document status and date:

Published: 01/01/2010

\section{Document Version:}

Publisher's PDF, also known as Version of Record (includes final page, issue and volume numbers)

\section{Please check the document version of this publication:}

- A submitted manuscript is the version of the article upon submission and before peer-review. There can be important differences between the submitted version and the official published version of record. People interested in the research are advised to contact the author for the final version of the publication, or visit the $\mathrm{DOI}$ to the publisher's website.

- The final author version and the galley proof are versions of the publication after peer review.

- The final published version features the final layout of the paper including the volume, issue and page numbers.

Link to publication

\section{General rights}

Copyright and moral rights for the publications made accessible in the public portal are retained by the authors and/or other copyright owners and it is a condition of accessing publications that users recognise and abide by the legal requirements associated with these rights.

- Users may download and print one copy of any publication from the public portal for the purpose of private study or research.

- You may not further distribute the material or use it for any profit-making activity or commercial gain

- You may freely distribute the URL identifying the publication in the public portal.

If the publication is distributed under the terms of Article 25fa of the Dutch Copyright Act, indicated by the "Taverne" license above, please follow below link for the End User Agreement:

www.tue.nl/taverne

Take down policy

If you believe that this document breaches copyright please contact us at:

openaccess@tue.nl

providing details and we will investigate your claim. 


\title{
Thermal Analysis of a Winding Turn-to-Turn Fault in PM Synchronous Machine
}

\author{
J. P. C. Smeets, J. Soulard and E. A. Lomonova
}

\begin{abstract}
This paper presents a detailed lumped parameter (LP) thermal model of an armature slot in a permanent magnet synchronous machine for traction applications. The model is used to investigate the temperature distribution in the slot after a turn-to-turn failure occurs. Steady-state analyses are conducted and a good agreement is found with FEM thermal simulations. The LP model is modified into a transient model and transient thermal analysis are conducted to predict the processing damage in the slot, which eventually might lead to a turn-to-tooth (ground) failure.
\end{abstract}

Index Terms - Synchronous machines, permanent magnet, thermal modeling, winding failures, turn-to-turn faults.

\section{INTRODUCTION}

$\mathrm{B}$ RUSHLESS permanent magnet synchronous machines (PMSM) are widely used in traction applications, since they offer the greatest efficiencies and the highest torque per volume [1]. Although a lot of research and development to fault tolerance machines has been done [2], a main concern remains about the behavior of the PMSM under faulty conditions. Common electromagnetic crashes are turn-to-turn and turn-to-tooth faults in the electrical machine and breakdown of the semiconductors in the power converter. Industrial machines have a failure rate of $1.0 \times 10^{-6}$ per hour due to turn-to-turn faults, which is equivalent to $16 \%$ of the total defects [3]. Turn-to-turn faults are mainly caused by insulation breakdown due to over temperature, ageing and vibrations in the machine. This type of defect is hard to detect and propagates rapidly in the remaining turns of the slot. Therefore, a turn-to-turn fault is the major cause of a motor breakdown.

The short-circuit current after a turn-to-turn fault reaches almost a value of $n_{s}$ times the rated current (with $n_{s}$ the number of conductors per slot) and is difficult to limit due to the uncontrollability of the field produced by the permanent magnets in the machine [4]. The mmf generated by the high value of short-circuit current in combination with the armature reaction $\mathrm{mmf}$, creates a temperature rise in the machine and could demagnetize the permanent magnets and thereby permanently damage the machine [5]-[6]. Furthermore, the increased copper losses due to the high short-circuit current, cause a temperature rise in the coils and the slot. This may result in an insulation breakdown between the turns and the tooth, which leads to a turn-to-tooth shortcircuit. This type of failure can be detected easily, since a current will flow from the tooth to the ground.

To evaluate the temperature distribution in the armature slot of a PMSM after a turn-to-turn failure, a detailed

J.P.C. Smeets and E.A. Lomonova are with the Electromechanics and Power Electronics group, Eindhoven University of Technology, Netherlands (email: j.p.c.smeets@tue.nl)

J. Soulard is with the Electrical Machines and Power Electronics group, KTH Royal Institute of Technology, Sweden lumped parameter (LP) thermal model of the slot needs to be obtained. Various LP thermal models of a PMSM can be found in literature [7]-[8]. The models are used for steadystate and transient thermal analysis of a complete machine. To reduce the complexity of the models, the machine is simplified into main components, each of them being modeled by a single thermal resistance [7]. The heat transfer is assumed to be mainly in radial direction leading to equivalent thermal networks for different angular spans of the motor, as was done in [8] for the PM motor.

Following the same modeling ideas as in [7] and [8], this paper presents a detailed LP thermal model of a slot of a PMSM. In section II, a detailed description of the slot and the thermal assumptions for the model are given. To simplify the lumped parameter model, symmetry in the slot is analyzed, and five equivalent thermal sub-models are presented in section III. The sub-models are duplicated to construct a complete LP model of the slot. In section IV, the steady-state thermal behavior of the slot after a turn-to-turn fault is simulated and verified with FEM thermal simulations. The LP thermal model is modified for transient analysis in section V. Finally, the transient thermal behavior of the slot after a turn-to-turn failure is evaluated in section VI to predict the processing damage in the slot.

\section{SLOT OF THE PMSM}

\section{A. Geometric description}

The geometry of a slot in the investigated PMSM is shown in Fig. 1. The slot contains two coils, each consisting of seven equivalent turns. The coils are separated by coil spacers and a wedge is placed between the airgap and the coils. To

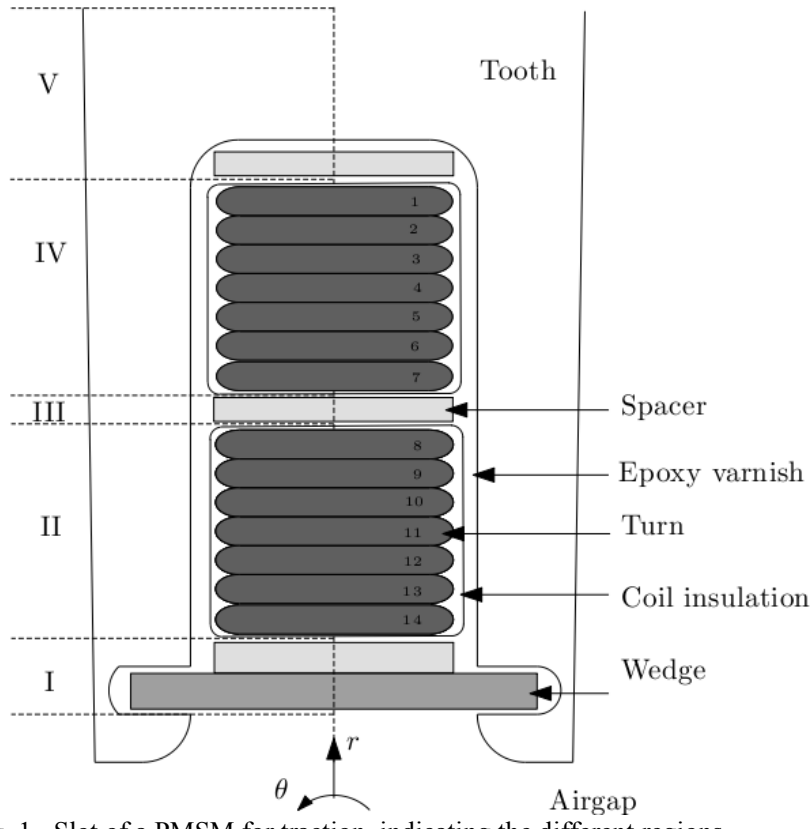

Fig. 1. Slot of a PMSM for traction, indicating the different regions. 
overcome a turn-to-turn and turn-to-tooth fault in the machine, several layers of insulation are placed around a coil. First of all, each turn has an individual layer of insulation. Second, a complete coil is covered with a bandage, and finally, the remaining area in the slot is filled with an epoxy varnish.

Due to the angular symmetry in the machine, only half of a slot needs to be modeled to obtain a complete overview of the temperature distribution in the PMSM.

\section{B. Thermal assumptions}

To simplify the LP thermal model, a number of assumptions are made:

- At the left and right boundaries of the model, as shown in Fig. 1, heat transfer is assumed in radial direction due to symmetry in the machine. This results in a boundary condition with no heat conduction, convection or radiation in angular direction.

- To simulate the worst-case steady-state scenario, no heat transfer is assumed into the airgap. This results in a boundary condition with no heat convection, conduction or radiation at bottom of the LP model.

- At the top of the stator yoke a fixed temperature of $100^{\circ} \mathrm{C}$ is assumed.

- Inside the model, heat transfer is assumed by means of conduction.

- Under normal conditions a total of $100 \mathrm{~W}$ is dissipated due to the copper losses in the turns of half the slot.

- An ambient temperature of $40^{\circ} \mathrm{C}$ is assumed in all the thermal simulations.

\section{Heat flow}

To model the temperature distribution in the slot, a FEM thermal model of the slot is created in Flux [9], based on the geometric layout and the boundary conditions. A steadystate simulation is conducted, where the losses are equally distributed over the turns and no turn-to-turn failure is assumed. The temperature distribution obtained from the FEM simulation is shown in Fig. 2. The figure shows heat transfer in radial direction in the tooth and in the coils. In the insulation layers between the coils and the tooth, heat is transferred in angular direction. The direction of the heat transfer is taken into account in the LP thermal model of the slot.

\section{LUMPED PARAMETER MODEL}

To reduce the complexity of the LP model of the slot, the geometry is divided into five regions and each region is individually modeled by a thermal equivalent circuit. The models are implemented in Portunus, a numerical simulation program from Adapted Solution distributed by CEDRAT [10]. Portunus has the possibility to create sub-models which can be connected to each other in a main model. This makes the program very suited for this construction approach of the LP thermal model.

The geometry of the slot is divided in radial direction into five regions, as shown in Fig. 1. Region I represents the part of the slot from the airgap up to the top coil, region II represents the top coil, region III represents the coil spacer,

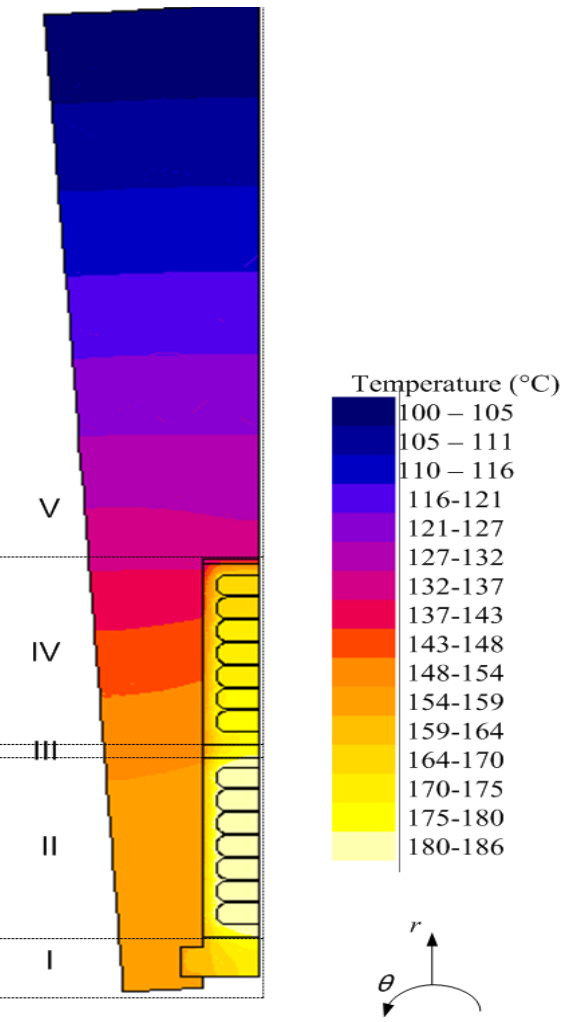

Fig. 2. Steady-state temperatures in the slot and tooth, ambient temperature of $40^{\circ} \mathrm{C}$.

region IV represents the bottom coil and region $\mathrm{V}$ represents the area between the bottom coil and the yoke of the machine. In angular direction, each region is created from the middle of the slot to the middle of the tooth. Region II and IV cover a large part of the slot, sharing many identical elements, and are therefore further divided into two subregions, as shown in Fig. 3. Sub-regions $A$ represent the coil insulation and sub-regions $B$ represent conductors including the insulation around it.

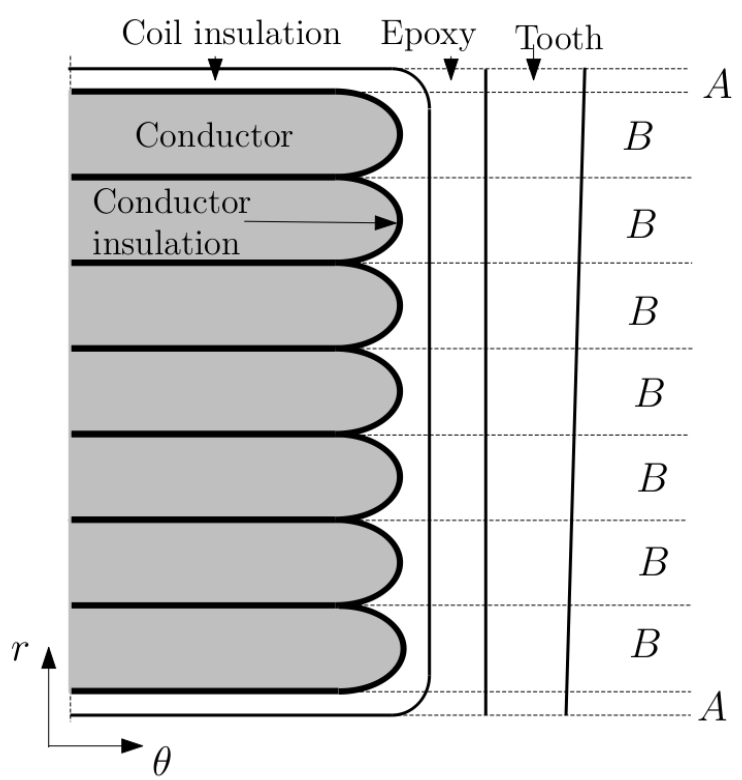

Fig. 3. Detailed model of a coil region.

The modeling of the slot results in five unique submodels, which are used multiple times to create the complete LP thermal model of a slot in the PMSM. In the next section each sub-model is described in more detail. 


\section{A. Detailed description of the sub-models}

A thermal equivalent circuit is created for each region, by representing the thermal properties of each type of material in the region by a conductive thermal resistance. The conductive thermal resistance, $R_{x}$, is defined by

$$
R_{x}=\frac{\Delta l}{k A}
$$

where $\Delta l$ is the length of the part, $k$ is the thermal conductivity of the material, $A$ is the cross section through which the heat is transferred, and subscript $x$ represents the modeled component.

The thermal equivalent circuit for region $I$ is shown in Fig. 4. Since no heat transfer is assumed into the airgap, no thermal connection into the airgap is created. From the airgap, the heat transfer in radial direction is separately modeled for the tooth and wedge, spacer and epoxy layer in the region.

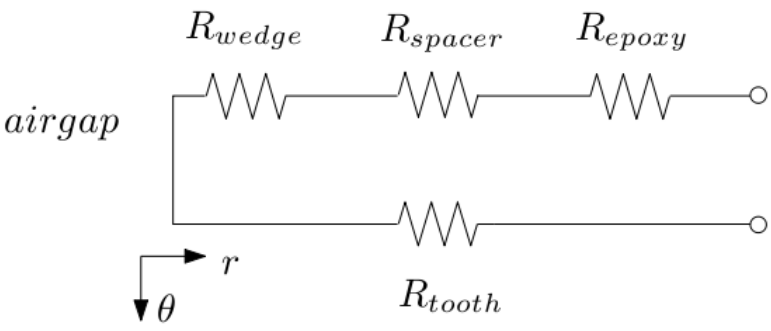

Fig. 4. Thermal equivalent circuit for region I.

In region III, heat is transfered in radial and angular direction in the coil spacer and in radial direction in the tooth, resulting in the thermal equivalent circuit shown in Fig. 5.

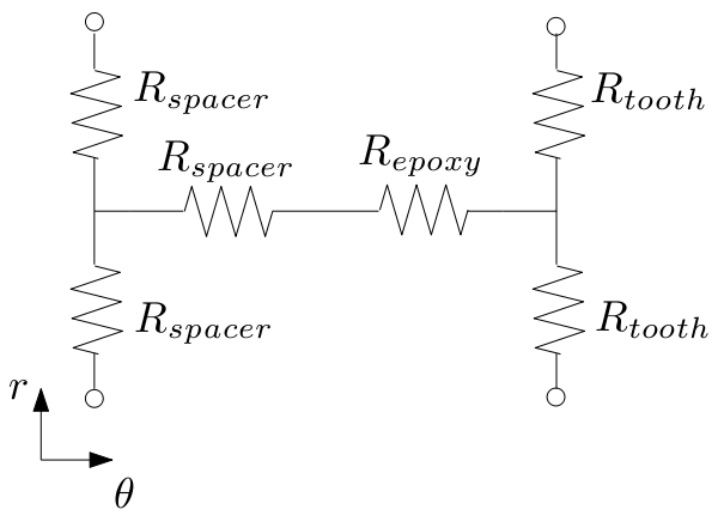

Fig. 5. Thermal equivalent circuit for region III.

In region $\mathrm{V}$, heat is transferred in radial direction through the spacer and the tooth to the yoke of the machine. Since the temperature distribution in the yoke of the machine is not a point of interest, it is modeled by a single thermal resistance, as shown in Fig. 6.

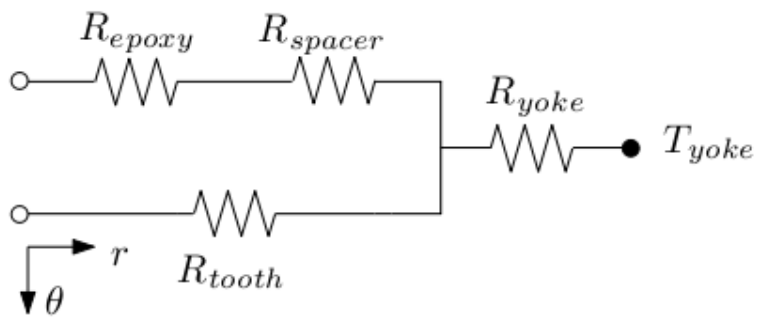

Fig. 6. Thermal equivalent circuit for region $\mathrm{V}$.

Region II and IV are constructed out of two sub-regions.
Figure 7 shows the thermal equivalent circuit for sub-region $A$. The region consists of a part of coil insulation and of a part of the tooth. Since both have a heat transfer in radial direction, no interconnection between the two materials has been made.

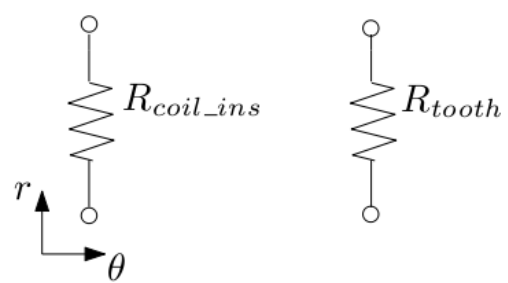

Fig. 7. Thermal equivalent circuit for sub-region $A$.

The thermal equivalent circuit of sub-region $B$ is shown in Fig. 8. The copper losses in the conductor are modeled by an equivalent thermal heat source, $q$. The source is connected to the thermal resistances of the insulation around the conductor. In this layer of insulation, heat is transferred in radial and angular direction. Furthermore, in angular direction heat transfer is also modeled through the different layers of insulation from the conductor to the tooth. In the tooth the heat is transferred again only in radial direction.

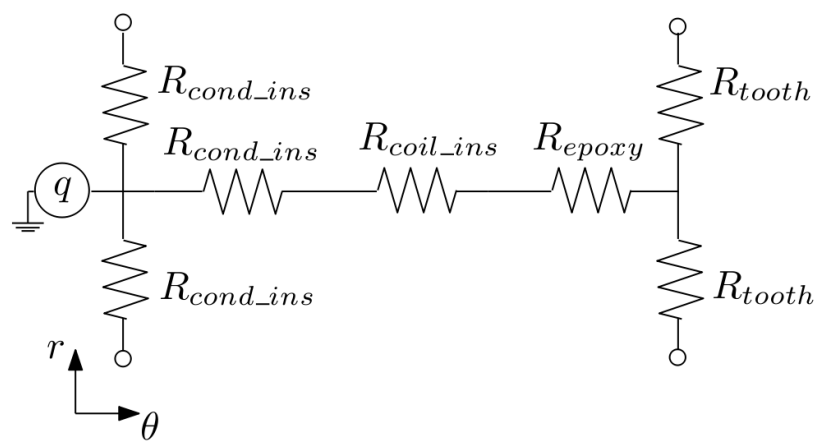

Fig. 8. Thermal equivalent circuit for sub-region $B$.

Finally, the different regions are used as building blocks to create the complete LP thermal model of the slot, which is schematically shown in Fig. 9. An equivalent subdivision similar to region $I I$ is used in region $I V$ and therefore, not presented in the figure.

\section{B. Model verification}

To validate the LP model a steady-state simulation is conducted and compared with the FEM thermal model. In both models the temperature is obtained in the middle of each conductor and at the same radius in the middle of the tooth. The temperatures in the conductors and tooth are shown in Fig. 10 and in Fig. 11, respectively. Between the LP and FEM model, a maximal error of $1^{\circ} \mathrm{C}$ is found in the temperatures in the conductors and $0.25^{\circ} \mathrm{C}$ in the temperatures in the tooth. A good agreement is found between the temperatures in the LP and the FEM model.

\section{STEADY-STATE SHORT-CIRCUIT SIMULATIONS}

A turn-to-turn failure can occur in each of the 14 turns in slot. To find the worst-case scenario, a turn-to-turn failure in each of the 14 turns is individually simulated under steadystate. In this series of simulations, $60 \mathrm{~W}$ is applied to the conductor in the faulted turn and no copper losses are assumed in the remaining conductors. 


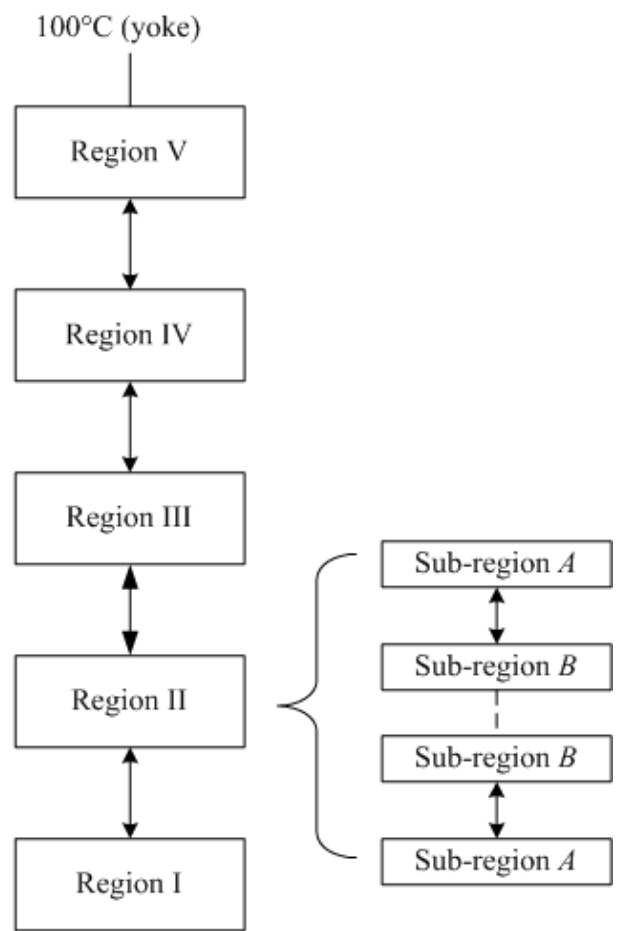

Airgap (no heat transfer)

Fig. 9. Schematic overview of the LP thermal model.

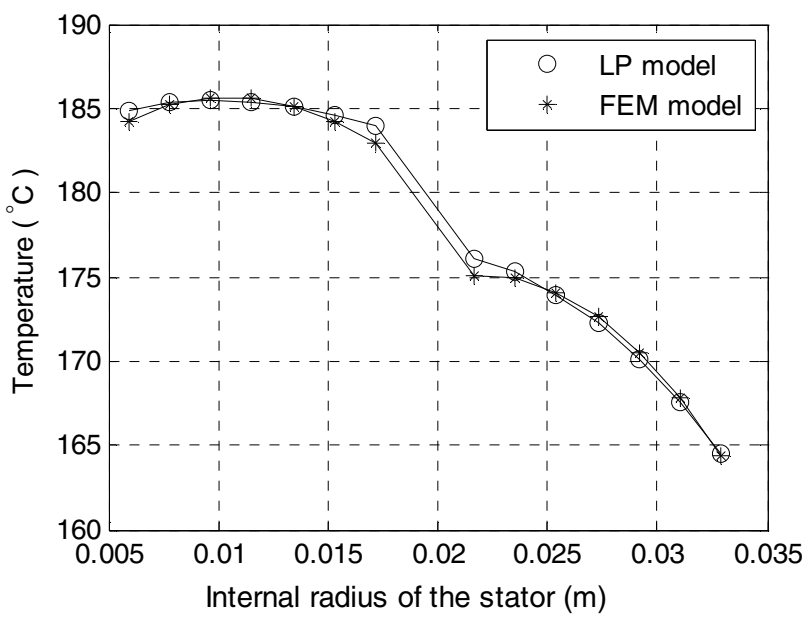

Fig. 10. Temperature in the conductors, ambient temperature $40^{\circ} \mathrm{C}$.

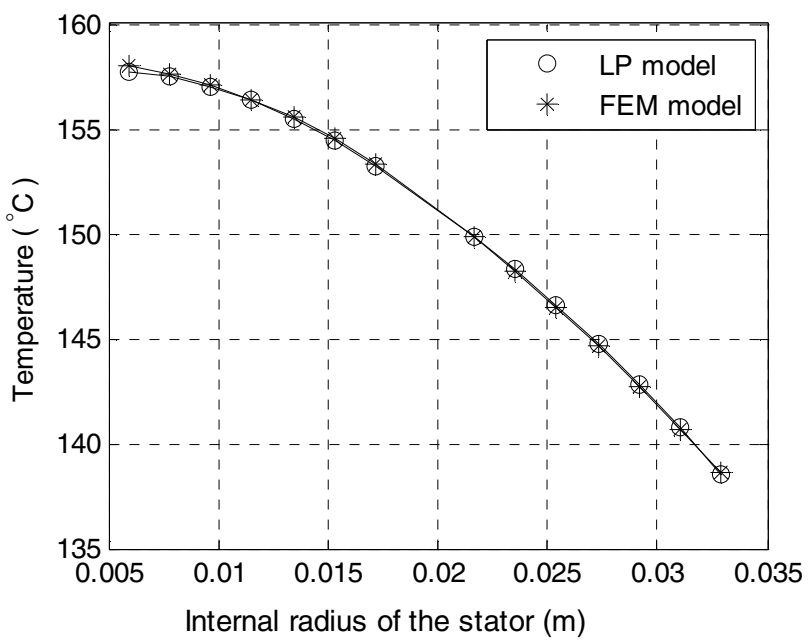

Fig. 11. Temperature in the tooth, ambient temperature $40^{\circ} \mathrm{C}$.
The simulations are conducted and the temperature is obtained in the middle of each conductor. The complete set of steady-state temperatures from all 14 simulations is shown in Fig. 12, where each curve represents a single simulation. The black dot indicates in which conductor the turn-to-turn failure is assumed.

From the figure a number of conclusions can be drawn:

- Higher temperatures after a turn-to-turn failure can be obtained in the conductors in the top part of the slot, i.e. close to the airgap.

- A turn-to-turn failure in one half of the slot has hardly influence on the temperature rise in the other half. This shows that the coil spacers are good thermal isolators.

Overall, the highest temperature is found, during a turn-toturn failure in the closest conductor to the airgap. A turn-toturn failure in this turn will be referred as the worst-case scenario.

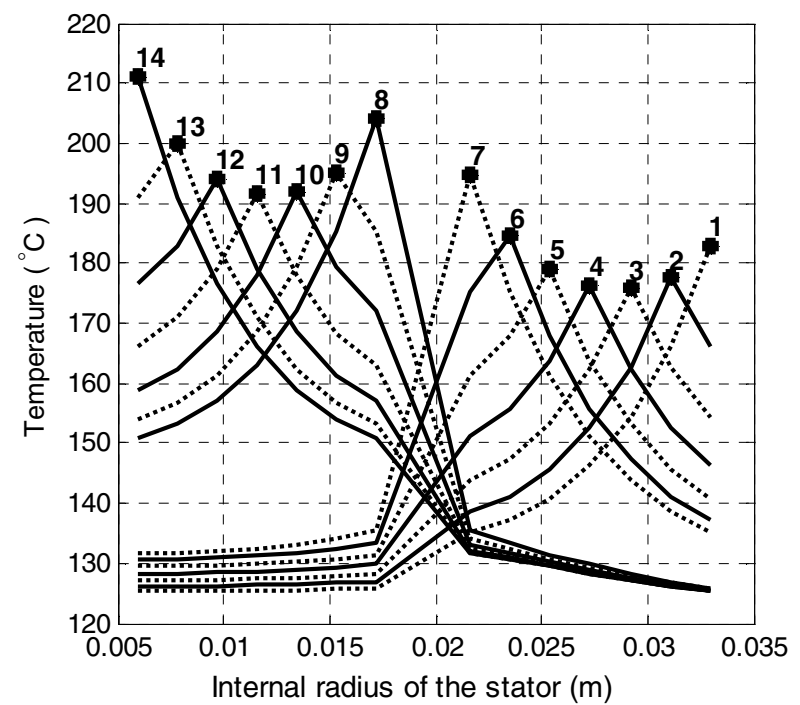

Fig. 12. Temperature in the conductors, the turn-to-turn failure is assumed in the conductor indicated with the black dot, ambient temperature $40^{\circ} \mathrm{C}$.

\section{A. Validation}

To verify the steady-state simulation for the worst-case scenario, a similar simulation is conducted with the FEM thermal model. The temperatures in the middle of the conductors are obtained from both models and shown in Fig. 13 , and a good agreement is reached again.

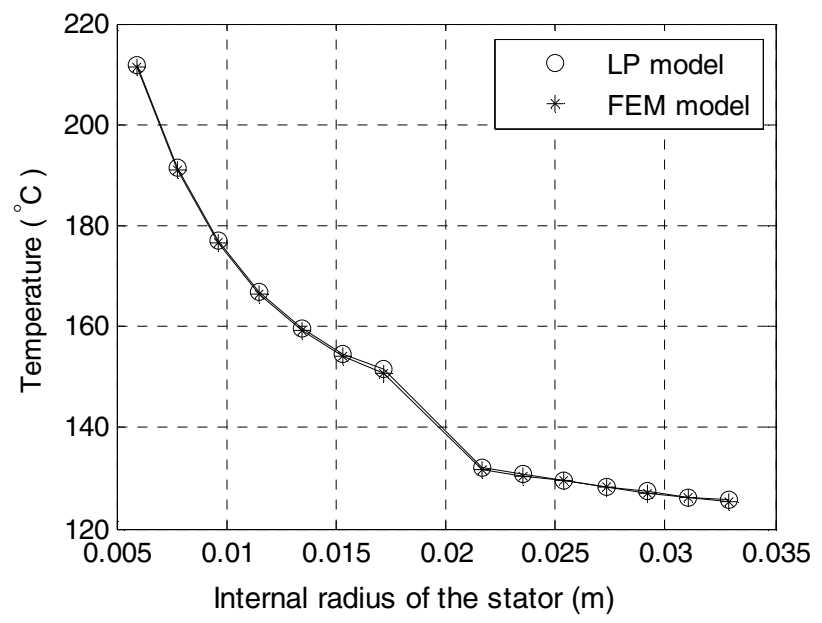

Fig. 13. Temperature in the conductors after a turn-to-turn failure in conductor 14 , ambient temperature $40^{\circ} \mathrm{C}$. 


\section{TRANSIENT LUMPED PARAMETER MODEL}

A turn-to-turn failure is hard to detect and can produce major damage to the machine before a turn-to-tooth failure is noticed. To investigate the temperature increase as a function of time after a turn-to-turn failure, the steady-state model is modified into a transient model. In the next sections, the main modifications are described.

\section{A. Modification to the LP thermal model}

Three modifications are applied to the steady-state LP thermal model. First, thermal capacities are added in the LP model to allow heat storage in the different components. The thermal capacity of a component can be obtained by

$$
C_{x}=C_{p} \rho V \text {, }
$$

where $C_{p}$ is the material heat capacity in $(\mathrm{J} / \mathrm{kg} \mathrm{deg}), \rho$ is the mass density and $V$-the volume of the component. In subregion $B$, heat capacity is added to the conductor and to the tooth and neglected in the insulation and epoxy layers in the region. The modified thermal equivalent circuit for subregion $B$ is shown in Fig. 14. Furthermore, in other regions thermal capacity is added to the different spacers and parts of the tooth since they cover a large volume, again thermal capacity is neglected in the insulation layers.

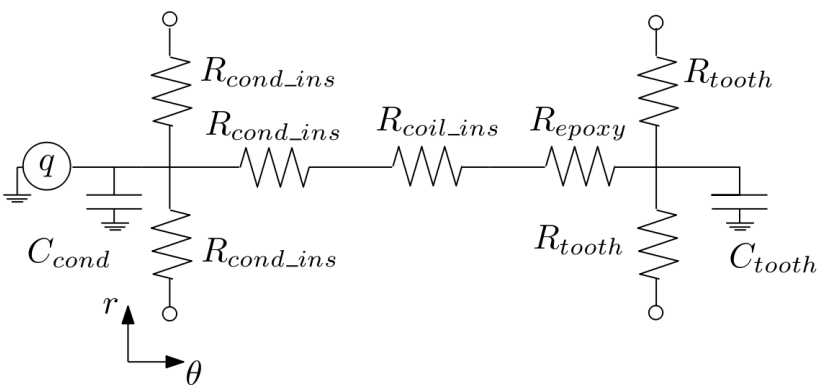

Fig. 14. Modified thermal equivalent circuit of sub-region $B$ for transient modeling.

Second, the thermal heat source is made proportional to the current flowing through the turn. The transient heat source is shown in Fig. 15. The model has an electric network which consists of a current source, $I_{\text {turn }}$, and a temperature dependent resistance, $R_{\text {turn }}$. The wattmeter, $W M$, transfers the electrical power into an equivalent thermal dissipation and feeds this into the thermal network. Meanwhile, the temperature in the thermal network, $T_{\text {turn }}$, is obtained and used to modify the value of $R_{\text {turn }}$, which increases the electrical dissipation and vice versa.

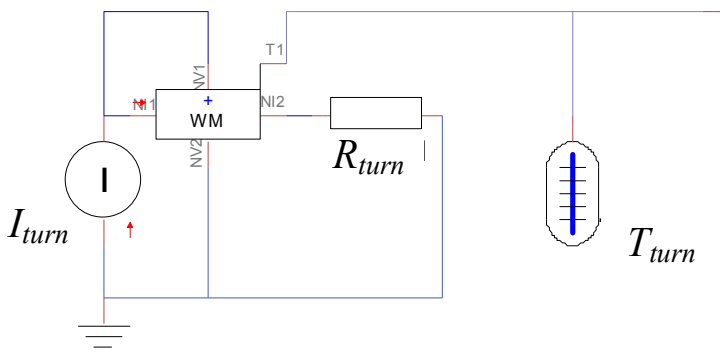

Fig. 15. Transient thermal heat source in Portunus software.

Finally, several state machines are inserted in the LP model. One state-machine is used to change the current in each individual turn as a function of the number of shortcircuited turns. The amplitude of the short-circuit currents, $I_{s c}$, is obtained from FEM simulations of the complete machine, in which each time a different number of turns is short-circuited [2]. The current amplitude per turns is shown in Table I.

\begin{tabular}{|c|c|}
\hline$\#$ short-circuited turns & $I_{s c}$ per turn $(\mathrm{kA})$ \\
\hline 1 & 1.67 \\
\hline 2 & 1.00 \\
\hline 3 & 0.69 \\
\hline 4 & 0.53 \\
\hline 5 & 0.43 \\
\hline 6 & 0.36 \\
\hline 7 & 0.31 \\
\hline
\end{tabular}

It is assumed that the insulation material looses its thermal properties after it has reached a temperature of $220^{\circ} \mathrm{C}$. Therefore, a second state machine is inserted into the model to change the thermal properties of the insulation during the simulation if the middle of the part reaches the maximal temperature.

\section{B. Boundary conditions}

Beside modifications of the model, the boundary condition at the airgap is also modified. Due to the rotating of the rotor, natural convection is assumed between the airgap and the wedge and tooth in region $A$.

\section{TRANSIENT SHORT-CIRCUIT SIMULATION}

A transient simulation of the worst-case scenario is conducted to obtain the damage in the slot, before a turn-totooth fault occurs. The transient simulation starts from the steady-state temperature and after two seconds the initial failure appears in the conductor closest to the airgap. During the simulation the temperatures in the conductors are obtained as a function of time (shown in Figs. 16 and 17).

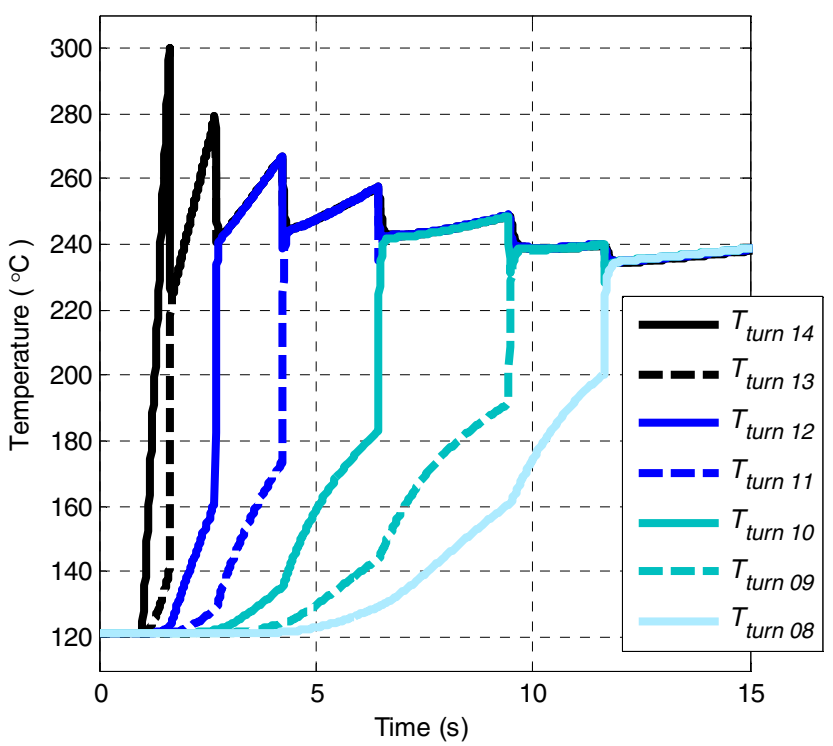

Fig. 16. Simulated values of temperatures in the turns during the first 15 seconds of the transient performance. A turn-to-turn failure occurs in turn 14 after two seconds, ambient temperature $40^{\circ} \mathrm{C}$.

Figure 16 shows the first 15 seconds of the transient simulation. After two seconds a turn-to-turn failure occurs in turn 14 , which immediately causes a temperature rise in the turn. After 0.6 seconds besides the turn-to-turn failure, the insulation between turns 13 and 14 reaches a temperature of 


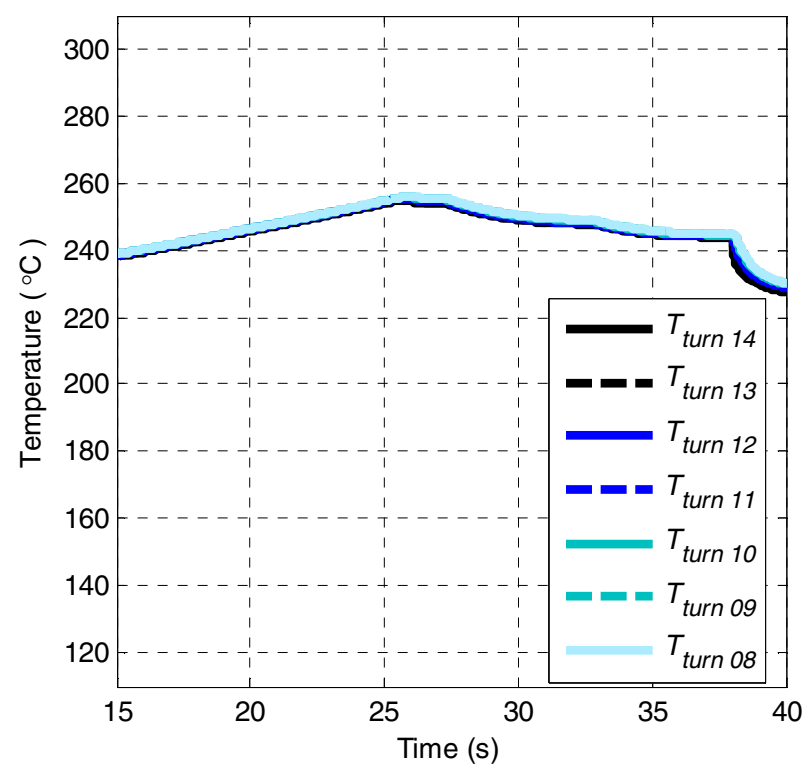

Fig. 17. Temperatures in the turns during the remaining 25 seconds of the transient simulation, ambient temperature $40^{\circ} \mathrm{C}$.

$220^{\circ} \mathrm{C}$ and both turns are short-circuited. The figure shows that the temperature in both turns averages. This process continues and after twelve seconds of simulation, all turns in the top coil have been short-circuited with each other.

Figure 17 shows the temperature development for the next 25 seconds of the transient behavior. The temperature in the turns is rising slowly and decreasing when the coil insulation gets locally damaged. Finally, 37 seconds after the turn-to-turn failure, the temperature drops significantly since the complete insulation between turn 14 and the tooth is damaged, resulting in a turn-to-tooth fault.

\section{CONCLUSION}

A detailed steady-state and transient lumped parameter thermal model of an armature slot in a permanent magnet synchronous machine has been presented in this paper. The complexity of the model has been reduced by developing five different thermal equivalent models. Good agreement has been found between steady-state LP model and a FEM thermal model.

The steady-state model has been modified into a transient model, which has been used to predict the damage caused in the slot after a worst-case turn-to-turn failure. It can be concluded that the initial turn-to-turn failure most likely spreads into the other conductors in the same slot, finally leading to a turn-to-tooth failure if it is not detected in time.

It should be noticed that the thermal assumptions made to the insulation material have not been verified experimentally. However, the interest of the investigation lies in the modeling principles and implementation of a highly non-linear combined electromagnetic and thermal system, rather than in the numerical results of the case study.

\section{ACKNOWLEDGMENT}

This project has been conducted as a collaboration between the Royal Institute of Technology and the Eindhoven University of Technology within the Swedish research program "The Green Train". The authors would like to thank Bombardier Transportation as well as Thomas Barucki, Adapted Solutions, and Dave Staton from Motor Design for their contributions to the study.

\section{REFERENCES}

[1] P.H. Mellor, T.J. Allen, R. Ong, Z. Rahman, "Faulted behavior of permanent magnet electric vehicle traction drives," IEEE International Electric Machines and Drives Conference, vol. 1, pp. 554-558, Jun. 2003.

[2] J.A. Haylock, B.C. Mecrow, A.G. Jack and D.J. Atkinson, "Operation of Fault Tolerant Machines With Winding Failure," IEEE Trans. on Energy Conversion, vol. 14, no.4, pp. 1490-1495, Dec. 1999.

[3] B.C. Mecrow, D.J. Atkinson, A.G. Jack, S. Green, J.A. Haylock and J. Coles, "The need for fault tolerance in an aeroengine electric fuel control system," IEE Colloquium on Electrical Machines and System for the More Electric Aircraft, pp. 9/1-9/5, 1999.

[4] J. Chai, J. Wang, Z. Sun and D. Howe, "Analytical prediction of interturn short-circuit current in fault-tolerant permanent magnet brushless machines," $4^{\text {th }}$ IET conference on Power Electronics, Machines and Drives, pp. 1-5, 2008.

[5] C. Gerada, K. Bradley and M. Sumner, "Winding turn-to-turn faults in permanent magnet synchronous machines," IEEE Industry Application Annual Meeting, vol. 5, pp. 1029-1036, 2005.

[6] J. Makarovic, "Lightweight positioning: Design and optimization of an actuator with two controlled degrees of freedom." $\mathrm{PhD}$ Thesis Eindhoven University of Technology, September 2006.

[7] P.H. Mellor, D. Roberts and D.R. Turner, "Lumped parameter thermal model for electrical machines of TEFC design," IEEE Procedings- $B$, vol. 138, no. 5, pp. 205-218, Sep. 1991.

[8] A.M. El-Refaie, N.C. Harris, T.M. Jahns and K.M. Rahman, "Thermal analysis of multibarrier interior PM synchronous machine using lumped parameter model," IEEE Transactions on Energy Conversion, vol. 19, no. 2, pp. 303-309, June 2004.

[9] Cedrat, FLUX 102 D User's guide, France, June 2009

[10] Adapted-solutions, User's Guide Portunus, 2008

\section{BIOGRAPHIES}

Johan Smeets was born in Eindhoven, The Netherlands in 1985. He received his M.Sc. degree in 2009 from the Eindhoven University of Technology and is currently working as a $\mathrm{PhD}$-student at the same university.

Juliette Soulard received her $\mathrm{PhD}$ degree in 1998 from University of Paris VI, France. Since then, she has been working at the Royal Institute of Technology, Stockholm, Sweden. She is associated professor, leading the research group High Performance Electrical Machines and Drives. She was part of a dedicated project within the Swedish "Green train" in 2007 and 2008 , investigating system aspects in PM motors for traction applications.

Elena Lomonova was born in Moscow, Russia. She received the M.Sc. (cum laude), Ph.D. (cum laude) degrees in Electromechanical Engineering, all from the Moscow State Aviation Institute (TU), Russia in 1982, 1993, respectively. She is currently Professor at the Eindhoven University of Technology, the Netherlands. She has worked on electromechanical actuators design, optimization and development of advanced mechatronics systems. 